\title{
OPEN Recovery and analysis of ancient beetle DNA from subfossil packrat middens using high-throughput sequencing
}

\author{
Aaron D. Smith ${ }^{1,10 \bowtie}$, Marcin J. Kamiński ${ }^{1,2,10}$, Kojun Kanda ${ }^{3}$, Andrew D. Sweet ${ }^{1,4}$, \\ Julio L. Betancourt ${ }^{5}$, Camille A. Holmgren ${ }^{6}$, Elisabeth Hempel ${ }^{7,8}$, Federica Alberti ${ }^{7,9}$ \& \\ Michael Hofreiter ${ }^{7}$
}

The study of ancient DNA is revolutionizing our understanding of paleo-ecology and the evolutionary history of species. Insects are essential components in many ecosystems and constitute the most diverse group of animals. Yet they are largely neglected in ancient DNA studies. We report the results of the first targeted investigation of insect ancient DNA to positively identify subfossil insects to species, which includes the recovery of endogenous content from samples as old as $\sim 34,355 \mathrm{ybp}$. Potential inhibitors currently limiting widespread research on insect ancient DNA are discussed, including the lack of closely related genomic reference sequences (decreased mapping efficiency) and the need for more extensive collaborations with insect taxonomists. The advantages of insect-based studies are also highlighted, especially in the context of understanding past climate change. In this regard, insect remains from ancient packrat middens are a rich and largely uninvestigated resource for exploring paleo-ecology and species dynamics over time.

The study of ancient DNA (aDNA) has fascinated both researchers and the public ever since the first reports were published exploring its feasibility ${ }^{1}$. Progress in molecular techniques and verification protocols have enabled scientists to publish reliable aDNA datasets ${ }^{2,3}$, which have been employed in a variety of biological studies ${ }^{4}$. While the majority of available aDNA data are from mammals, including hominins, publications on birds ${ }^{5}$, molluscs $^{6}$, plants $^{7}$, fungi ${ }^{8}$, viruses ${ }^{9}$ and other organisms are also available.

Besides a few contributions in the 1990's that are now widely accepted to represent contamination ${ }^{10}$, only a handful of replicable insect aDNA studies exist ${ }^{11-13}$. To date, the oldest (>100,000 years) invertebrate DNA sequences were obtained from deep ice core samples from Southern Greenland ${ }^{13}$. However, only partial cytochrome oxidase subunit 1 (COI) sequences were recovered, and the authors were unable to assign taxa below the ordinal or familial level. The only other invertebrate aDNA study used permafrost sediment samples, ranging from ca. 10,000 to 48,000 years, and yielded partial COI and 16S sequences for different beetle species ${ }^{14}$. However, the estimated probabilities of assigning sequences to a given taxonomic level were low. These studies illustrate a main trend in insect aDNA studies, which have been mostly focused on demonstrating the feasibility of extracting endogenous DNA rather than investigating particular biological problems-unlike published aDNA studies on vertebrates ${ }^{4}$. The only available insect aDNA paper dealing with a phylogenetic question at the species level was based on 400-year-old samples ${ }^{12}$.

One of the main reasons why insect aDNA is not already implemented in a wide variety of biological studies is likely the relative scarcity of subfossil insect material from which DNA can be recovered. Generally, the bestpreserved samples, in terms of DNA stability, originate from cold environments at high latitudes and elevations ${ }^{15}$.

${ }^{1}$ Department of Entomology, Purdue University, 901 W. State Street, West Lafayette, IN 47907, USA. ${ }^{2}$ Zoological Museum, Museum and Institute of Zoology, Polish Academy of Sciences, Wilcza 64, 00-679, Warszawa, Poland. ${ }^{3}$ USDA Systematic Entomology Laboratory, C/O Smithsonian Institution, National Museum of Natural History, Washington, DC, USA. ${ }^{4}$ Department of Biological Sciences, Arkansas State University, State University, AR 72467, USA. ${ }^{5}$ Science and Decisions Center, U.S. Geological Survey, Reston, VA, USA. ${ }^{6}$ Department of Geography and Planning, SUNY Buffalo State College, Buffalo, NY, USA. ${ }^{7}$ Institute for Biochemistry and Biology, University of Potsdam, Potsdam, Germany. ${ }^{8}$ Museum Für Naturkunde, Berlin, Leibniz Institute for Evolution and Biodiversity Science, Berlin, Germany. ${ }^{9}$ Reiss-Engelhorn-Museen, Mannheim, Germany. ${ }^{10}$ These authors contributed equally: Aaron D. Smith and Marcin J. Kamiński. ${ }^{\circledR}$ email: pimeliinae@purdue.edu 


\begin{tabular}{|c|c|c|c|c|c|c|c|c|c|}
\hline $\begin{array}{l}\text { Calibrated } \\
\text { age midpoint } \\
\text { (ybp) }\end{array}$ & $\begin{array}{l}\text { Original } \\
\text { sample code }\end{array}$ & Origin & $\begin{array}{l}\text { Available/used }{ }^{*} \\
\text { body fragments }\end{array}$ & $\begin{array}{l}\text { DNA extract } \\
\text { concentration } \\
(\mathrm{ng} / \mu \mathrm{l})\end{array}$ & $\begin{array}{l}\text { Library } \\
\text { concentration } \\
(\mathrm{ng} / \mu \mathrm{l})\end{array}$ & $\begin{array}{l}\text { Amount used } \\
\text { for lib. prep }\end{array}$ & $\begin{array}{l}\text { Total \# of } \\
\text { recovered } \\
\text { reads }\end{array}$ & $\begin{array}{l}\text { \# of aligned } \\
\text { genomic } \\
\text { reads }\end{array}$ & $\begin{array}{l}\text { \# of aligned } \\
\text { mitochondrial } \\
\text { reads }\end{array}$ \\
\hline 1615 & $53^{23}$ & $\begin{array}{l}\text { Joshua Tree } \\
\text { National Park } \\
\text { (JTNP) (Jumbo } \\
\text { Rock) }\end{array}$ & $\begin{array}{l}\text { Pronotum, } \\
\text { coxa }+ \text { femur }+ \text { tibia }\end{array}$ & 0.558 & 10.9 & $\begin{array}{l}\text { Whole extract } \\
(20 \mu \mathrm{l})\end{array}$ & $2,252,684$ & $3511(0.156 \%)$ & 6777 \\
\hline 2035 & $74^{23}$ & $\begin{array}{l}\text { JTNP (Jumbo } \\
\text { Rocks North) }\end{array}$ & Femur + tibia* & 1.06 & 16.2 & $11 \mu \mathrm{l}$ & $2,262,666$ & $3973(0.176 \%)$ & 12,073 \\
\hline 8480 & $80 \mathrm{~B}^{23}$ & $\begin{array}{l}\text { JTNP (Hidden } \\
\text { Valley) }\end{array}$ & Femur + tibia* & NM & 12.9 & $\begin{array}{l}\text { Whole extract } \\
(20 \mu \mathrm{l})\end{array}$ & $2,386,019$ & $712(0.030 \%)$ & 601 \\
\hline 16,610 & $41 \mathrm{~B}[24]$ & $\begin{array}{l}\text { Sierra Juarez } \\
\text { (Guadalupe } \\
\text { Canyon) }\end{array}$ & Femur + tibia* & 0.548 & 19.3 & $\begin{array}{l}\text { Whole extract } \\
(20 \mu \mathrm{l})\end{array}$ & - & - & - \\
\hline 34,355 & $60 \mathrm{~B}[23]$ & $\begin{array}{l}\text { JTNP (Indian } \\
\text { Cove) }\end{array}$ & $\begin{array}{l}\text { Abdominal ven- } \\
\text { trites, pronotum, } \\
\text { femur + tibia* }(3 \\
\text { sets) }\end{array}$ & 1.99 & 10.5 & & $2,471,490$ & $133(0.005 \%)$ & 45 \\
\hline- & Ex Blk1 & - & - & NM & 3.34 & $\begin{array}{l}\text { Whole extract } \\
(20 \mu \mathrm{l})\end{array}$ & 473,099 & 0 & 1 \\
\hline- & Libr Blk & - & - & - & 2.88 & - & 292,658 & 0 & - \\
\hline
\end{tabular}

Table 1. Summary of ancient samples reported in this study. ${ }^{\star}$ Body part used for extraction; + intact body parts; NM not measurable; Ex and Libr Blk extraction and library blanks; ${ }^{a}$ Endogenous genomic DNA content measured as the total number of recovered reads mapped to the Tribolium castaneum genome; ${ }^{\text {N Number of }}$ reads mapped to the reference mitogenome of Philolithus actuosus.

However, another, largely untapped source of well-preserved ancient specimens (including insects) are subfossilized rodent middens $s^{9,11,16}$. Ancient rodent middens are amalgamations of plant and animal remains embedded in blocks of crystallized urine preserved in aridland caves and rock shelters ${ }^{17}$. Distributed across arid parts of Australia (built by Leporillus), Central Asia (Alticola, Ochotona), North (Neotoma) and South America (Abrocoma, Phyllotis), and southern Africa (Petromus), middens are frequently used to investigate myriad ecological responses to environmental change over the last 50,000 years ${ }^{18}$. The feasibility of extracting insect aDNA out of this paleontological resource has already been shown ${ }^{19}$. However, the amount of sequenced DNA in these studies was insufficient for species-level identification.

Previous insect aDNA papers have been based on Sanger sequencing ${ }^{11-14}$ or metagenomic methodologies ${ }^{16,19}$. This translates directly to the above-mentioned scarcity of available sequences. However, multiple recent studies of historical materials (museum specimens) have shown the feasibility of recovering and assembling longer DNA fragments from insect specimens using high-throughput shotgun sequencing methods ${ }^{20-22}$. In addition, extraction and library preparation protocols for aDNA analyses are constantly being developed towards maximizing yield from older samples ${ }^{3}$. This theoretically provides a firm background for molecular studies using subfossilized insects, while also exploring the ability of existing aDNA extraction methods to recover sequence data from relatively small specimen fragments.

The present paper reports the successful extraction and analysis of insect mitochondrial genomes and nuclear ribosomal DNA (28S) from ancient packrat (Neotoma) middens (up to 34,355 years before present, ybp) using single-stranded library preparation combined with high-throughput shotgun sequencing. Due to the amount of recovered data, specimen identifications were confirmed to the species level.

\section{Materials and methods}

Ancient samples. Studied insect subfossils originated from midden samples collected at Joshua Tree National Park in southeastern California (USA) and the eastern piedmont of Sierra Juarez in northern Baja California (Mexico) with calibrated median ages from 1615 to $34,355 \mathrm{ybp}$. As studies of plant macrofossils and pollen samples from those middens have been published, detailed technical descriptions of the investigated middens already exist ${ }^{23,24}$. However, a brief description is given here. From each midden a minimum of $500 \mathrm{~g}$ of material has been collected. Middens were first inspected and the rind was removed to rid the sample of modern contaminants. In the laboratory, middens were washed and dried. Subsequently the macrofossils were sorted and stored at room temperature in sterilized tubes. Material for radiocarbon dating (rodent fecal pellets or plant macrofossils) was pretreated at California State University, Long Beach, and measured at the W. M. Keck Carbon Cycle Accelerator Mass Spectrometry Laboratory at the University of California, Irvine. The Calib 5.0.2 Intcal04 calibration curve (Stuiver and Reimer, 1993) was used for samples $<21{ }^{14} \mathrm{C}$ ka BP and the CalPal-2007-Hulu curve was used for samples $>21{ }^{14} \mathrm{C}$ ka BP (www.calpal.de). Dates are reported herein as the midpoint of calibrated age ranges (Table 1 ).

Prior to this study, the subfossil arthropod samples were already separated and stored at room temperature in sterilized tubes ${ }^{23,24}$. These arthropod fragments were examined in their original vials before selecting five subfossils of Asidini (darkling beetles) for potential DNA extraction (Table 1). The samples were then examined separately outside the original vials to confirm identifications at Northern Arizona University (NAU), in a room without other arthropod specimens, using a sterilized microscope, nitrile gloves, and previously unused and sterilized forceps and disposable petri dishes. The samples, primarily legs, were identified as belonging to 
Philolithus actuosus based on the presence of several distinct morphological characters, particularly the lack of an apical protibial spine, the presence of crenulations along the inner tibial margins, and the rugosity and punctation on femora. These characters are sufficient to both identify Philolithus from other co-occurring genera, and to separate $P$. actuosus from $P$. carinatus, a similar species known from southern California. Post-examination at NAU, samples were resealed in sterile $1.5 \mathrm{ml}$ microtubes and sent to the University of Potsdam for extractions, where they were processed in the ancient DNA laboratory of the Evolutionary Adaptive Genomics research group. Prior to this, no samples representing the family Tenebrionidae were handled by this facility, while the distribution of the studied species is restricted to the southern Nearctic Realm, which precludes any forms of accidental contamination at this step.

Extraction, library preparation and sequencing. Ancient midden taxa. DNA was extracted by combining the protocols of Dabney et al. ${ }^{2}$ and Rohland et al. ${ }^{25}$ with a modified extraction buffer from Taron et al. ${ }^{26}$. Specifically, tibiae and femora were cut longitudinally and later incubated in $1 \mathrm{~mL}$ of extraction buffer $(5 \mathrm{M}$ GuSCN, $25 \mathrm{mM} \mathrm{NaCl}, 50 \mathrm{mM}$ Tris, $20 \mathrm{mM}$ EDTA, 1\% Tween-20, 1\% beta-Mercaptoethanol) for $20 \mathrm{~h}$ at $37^{\circ} \mathrm{C}$ on a rotating wheel. Subsequently, centrifugation was performed to pellet the remaining tissue, and the supernatant was combined with $13 \mathrm{~mL}$ of binding buffer (5 M guanidine hydrochloride, $40 \%$ isopropanol, $0.05 \%$ Tween-20, and $90 \mathrm{mM}$ sodium acetate). Purification was performed on a Zymo-Spin V Column reservoir combined with a Qiagen MinElute column. Two washing steps were performed using PE Buffer (Qiagen), followed by a drying spin for $1 \mathrm{~min}$ at 13,000 rpm. DNA was eluted twice, each using $12.5 \mu \mathrm{L}$ TET buffer $(10 \mathrm{mM}$ Tris- $\mathrm{HCl}, 1 \mathrm{mM}$ EDTA, $0.05 \%$ Tween-20), using a 10 min incubation time. Two blanks, one handled first and the other last, were included during the extraction process (Table 1). They were later merged into a single tube and processed along with the samples after determining that DNA concentration was too low in both to be measurable. An additional blank was also included for the library preparation steps.

Illumina sequencing libraries were prepared using a protocol based on single-stranded $\mathrm{DNA}^{3}$. The extracts were quantified using a Qubit 2.0 instrument (Fisher) with the dsDNA HS Assay kit (Table 1). The input volume for library preparation was adjusted to $13 \mathrm{ng}$ total input DNA to maximize the efficiency of the single-stranded ligation reaction ${ }^{3}$. Input DNA was first treated with uracil-DNA glycosylase and endonuclease VIII to remove uracils, which are produced from the deamination of cytosines in ancient or degraded DNA ${ }^{27-29}$. In this process, the input volume extractions were added to a mix containing $11 \mu \mathrm{l}$ nuclease free water, $8 \mu \mathrm{l}$ Circligase buffer II (10×), $4 \mu \mathrm{l} \mathrm{MnCl} 2(50 \mathrm{mM}), 0.5 \mu \mathrm{l}$ Endonuclease VIII $(10 \mathrm{U} \mu \mathrm{l}-1)$ and $0.5 \mathrm{Afu}$ UDG $(2 \mathrm{U} \mu \mathrm{l}-1)$ per sample ${ }^{30}$. This solution was incubated at $37^{\circ} \mathrm{C}$ for $1 \mathrm{~h}$.

Libraries were PCR amplified and indexed by adding $8 \mu$ Accuprime Pfx reaction mix (10×), $3.2 \mu \mathrm{l} 7$ indexing primer $(10 \mu \mathrm{M}) 3.2 \mu \mathrm{l}$ P5 indexing primer $(10 \mu \mathrm{M}), 0.8 \mu \mathrm{l}$ Accuprime Pfx polymerase $(2.5 \mathrm{U} \mu \mathrm{l}-1)$ and $44.8 \mu \mathrm{l}$ nuclease free water followed by a selected number of PCR cycles, involving denaturation for $15 \mathrm{~s}$ at $95^{\circ} \mathrm{C}$, annealing for $30 \mathrm{~s}$ at $60^{\circ} \mathrm{C}$ and primer extension for $1 \mathrm{~min}$ at $68^{\circ} \mathrm{C}$. The appropriate numbers of cycles were established using qPCR (PikoReal Real-Time PCR system, Thermo Fisher Scientific) analysis of the unamplified libraries to identify the cycle number corresponding to the point of inflection of the qPCR amplification curve, correcting for differing reaction volume and template amount in the subsequent library amplification PCR. After amplification, the indexed libraries were quantified using a Qubit with the dsDNA HS Assay kit (Table 1). For each library, 2.25-2.47 million 75 bp PE reads were sequenced on an Illumina NextSeq 500 sequencing platform at the University of Potsdam, Germany.

Museum and modern taxa The identities of the ancient insect fragments were tested in a phylogenetic context. The DNA alignment for phylogenetic inference included sequences from aDNA samples, two museum specimens of Philolithus actuosus - putative conspecifics to the subfossil fragments, and 15 additional Asidini, i.e., 13 species from the Southwest United States and two outgroup species from the Southern African genus Machla (Supplement 3), which were also in reference-based assemblies for the ancient samples.

DNA from both museum specimens of Philolithus actuosus was extracted under a UV-sterilized laminar flow hood with dedicated equipment using QIAamp DNA Micro kits (Qiagen) following the manufacturer's protocol with the addition of carrier RNA. DNA was extracted from head capsules, without grinding the cuticle, to minimize damage to specimens. Libraries were constructed using 30 to $50 \mathrm{ng}$ DNA with NEBNext ${ }^{\bullet}$ Ultra $^{\text {rs }}$ II DNA Library Prep Kits (New England Biolabs) following the manufacturer's protocols. Libraries were sequenced on an Illumina MiSeq maintained by the Environmental Genetics and Genomics Laboratory (Northern Arizona University, Flagstaff AZ), using 75 bp paired end runs.

Sequence data from other Asidini genera (Machla-TB17124, Pelecyphorus-TB21116A, and Stenomorpha-TB15559C) and one Philolithus aegrotus specimen (TB15569) were obtained using a low-coverage genome sequencing approach. DNA was extracted from the whole body to maximize DNA yield using DNeasy Blood and Tissue Kits (Qiagen) following the manufacturer's protocols. Cuticle was not ground to minimize damage to the specimens. Library preparations were performed with NEBNext ${ }^{\circ}$ Ultra $^{\text {Tn }}$ II DNA Library Prep Kits (New England Biolabs), following the manufacturer's protocols, on 300-1000 ug of DNA per specimen. Libraries were sequenced at the University of Arizona's Genomic and Technology Core Facility (UAGC) on an Illumina Hi-Seq using 150 bp paired end runs.

Molecular data for the remaining Philolithus specimens, excluding one Philolithus aegrotus (TB15569), were obtained using Sanger sequencing for mitochondrial (COI, COII, and 12S) and nuclear (28S) loci. DNA was extracted from heads using DNeasy Blood and Tissue Kits (Qiagen) following the manufacturer's protocols. PCR reactions were performed using primer pairs and thermocycler programs described in Kanda et al. ${ }^{20}$ and Kamiński et al..$^{22}$. PCR products were cleaned, quantified, and sequenced at the University of Arizona's Genomic and Technology Core Facility (UAGC) using a 3730 XL Applied Biosystems automatic sequencer. Chromatograms 
were assembled using Phred v. 0.020425. $\mathrm{c}^{31}$ and Phrap v. 0.990319 ${ }^{32}$, implemented in Mesquite's Chromaseq v. 1.5 package $^{33}$ with manual inspection.

Mitochondrial genome assembly. Before assembly, the modern, museum, and ancient libraries were trimmed using Trimmomatic v.0.36 ${ }^{34}$. For modern and museum libraries, trimming removed adapters, trailing bases below a PHRED quality of 3, sliding windows ( $4 \mathrm{bp}$ ) below an average PHRED quality of 15 , and any reads $<20 \mathrm{bp}$ after trimming. Ancient libraries were trimmed by removing adapters and reads $<30 \mathrm{bp}$. All trimmed libraries were then assessed using FastQC v.0.11.7 (Babraham Bioinformatics). The mitochondrial genomes of modern samples and the two most recent ancient samples ( $1615 \mathrm{ybp}$ and $\sim 2035 \mathrm{ybp})$ were assembled de novo using the multi-cell mode in SPAdes v.3.13.0 $0^{35}$. Assembled mitochondrial scaffolds were identified using BLAST searches against the published mitochondrial genome from Asbolus verrucosus (NC_027256). Mitochondrial genomes of the two museum specimens of Philolithus actuosus were then assembled by mapping reads to the modern $P$. aegrotus mitochondrial genome in MITObim v. $1.8^{36}$. Finally, mitochondrial genomes for the ancient samples were also assembled by mapping reads to the mitochondrial genome of the $P$. actuosus Joshua Tree specimen using the aln algorithm in BWA v.0.7.17 both with (default) and without seeding ${ }^{37}$. The two control blanks were also mapped to this reference. SAMtools v.1.8 $8^{38}$ was used to remove duplicate reads, sort reads, remove unmapped reads, and remove reads with Mapping Quality scores $<30$. BCFtools ${ }^{39}$ was then used to generate pileup files and consensus FASTA sequences for each filtered BAM file. To ensure reference mapped mitogenome sequences of ancient samples were not biased by the reference, each ancient library was also mapped to four additional mitogenomes from modern samples (Fig. 2a): P. aegrotus, Pelecyphorus contortus, Stenomorpha consobrina, and Machla setosa. Finally, the filtered BAM files were run against the P. actuosus reference in mapDamage v.2.0 $0^{40}$ to assess fragment lengths, breakpoints, and deamination (Supplement 6).

All mitochondrial genome assemblies (modern, museum, and ancient) were then annotated using the MITOS2 web server (http://mitos2.bioinf.uni-leipzig.de/index.py) ${ }^{41}$ and manual curation following the workflow outlined in Cameron ${ }^{42}$. Average sequencing depth for each mitochondrial genome assembly was calculated using SAMtools and per-base coverage was calculated using BEDTools v.2.29.0 ${ }^{43}$.

$28 \mathrm{~S}$ assembly and nuclear genome read-mapping. $\quad 28 \mathrm{~S}$ sequences were assembled from the Illumina libraries of modern, museum, and ancient samples using a read-mapping approach in BWA. Each modern sample was mapped to a $28 \mathrm{~S}$ sequence of the same genus generated from PCR and Sanger sequencing, while museum samples were mapped to the $28 \mathrm{~S}$ sequence assembled for $P$. aegrotus. To ensure that mapped sequences of ancient samples were not biased by the reference, each ancient library was mapped to $28 \mathrm{~S}$ sequences from $P$. actuosus, $P$. aegrotus, Pelecyphorus contortus, Stenomorpha consobrina, and Machla setosa (Fig. 2b). Resulting BAM files were sorted and filtered in SAMtools, and consensus sequences were generated using BCFTools.

To assess nuclear coverage of the ancient samples, Illumina libraries were mapped to the nuclear genome of Tribolium castaneum ${ }^{44}$ in BWA (again using both seed and seedless parameters) with the aln algorithm. SAMtools and BEDTools were then used to remove duplicate reads, sort reads, remove unmapped reads, filter $(\mathrm{MQ}<30)$, and calculate sequencing depth and proportions of reads that mapped to the reference.

Phylogenetic analysis. The resulting sequences were aligned by locus in MAFFT V7.402 $2^{45}$ and then concatenated in Mesquite $3.61^{33}$ into a single matrix (13,926 bp) for phylogenetic analyses. Data partitions and models of sequence evolution were assessed with Partitionfinder v. 2.1.1 as implemented on CIPRES ${ }^{46}$, with the concatenated dataset initially partitioned by gene and codon position (for protein coding genes) using the greedy searches and the Bayesian information criteria (BIC). The best-fit partitioning scheme is presented in Supplement 5.

Phylogenetic analyses were conducted on CIPRES using MrBayes v. 3.2.7 $\mathrm{a}^{47}$ and IQ-Tree v. 1.6.10 ${ }^{48}$. Bayesian analyses were performed with two independent runs, each with four chains sampled every 1000 generations after a burnin of $25 \%$, with convergence checked using the average standard deviation of split frequencies and in Tracer v. 1.7.1 ${ }^{49}$. Posterior probability (PP) values were used to assess branch support for the resulting Bayesian consensus topology. Maximum likelihood (ML) analyses in IQ-Tree were run with edge-unlinked partition models (-spp), with partitions and models reassessed in IQ-Tree prior to phylogenetic analysis. Branch support was estimated in IQ-tree using 20,000 ultrafast bootstrap replicates ${ }^{50}$, with the 'bnni' approach to reduce the risk of overestimating support values.

\section{Results}

aDNA sequence assembly. To estimate the overall endogenous DNA content of the studied ancient samples (Table 1), recovered sequence data were mapped to the only available Tenebrionidae nuclear genome assembly-that from Tribolium castaneum ${ }^{44}$-a distantly related species from the subfamily Tenebrioninae, that likely diverged from Pimeliinae (the subfamily Asidini belongs to) $\sim 145$ million years ago ${ }^{51}$. As such, the presence of endogenous beetle DNA should be interpreted qualitatively, i.e., beetle DNA was present, rather than quantitatively (though relative quantities are shown) ${ }^{52}$. The endogenous content recovered from the samples varied between $0.005-0.176 \%$ (Table 1 ). For phylogenetic purposes, a portion of the nuclear ribosomal gene $28 \mathrm{~S}$ sequence (D1-D3 region) was also recovered from the samples dating back to 34,355 ybp as well as mitogenomic data.

Mitochondrial genomes were assembled and annotated for radiocarbon dated samples from $\sim 1615$ and 2035 ybp (Fig. 1). The assembled mitochondrial genomes were 16,076 and 16,114 bp long, respectively. The average read depth was 21 -fold for the $\sim 1615$, and 43 -fold for the $\sim 2035$ ybp samples (Fig. 1 ). The nucleotide composition of the recovered mitogenomes were heavily AT-biased (average AT content $=72.8 \%$ ). The recovered gene 

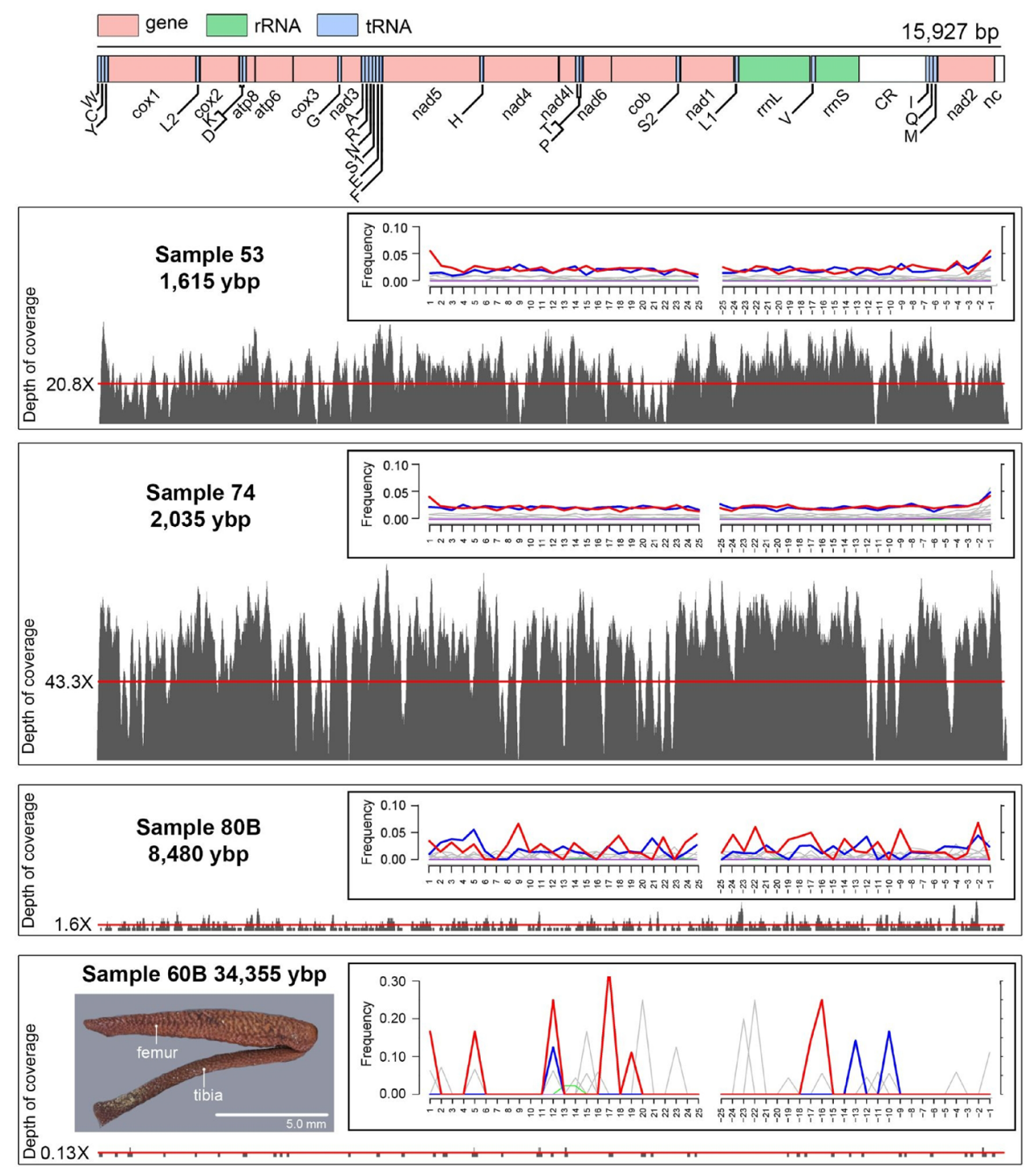

Figure 1. Gene arrangement and read depth along reconstructed ancient mitochondrial genomes. All aDNA reads were mapped in BWA v.0.7.17 to the Philolithus actuosus TB20958 (Tenebrionidae: Asidini) mitogenome. Asterisk indicates samples containing $>1 \%$ ambiguous sequences from lack of coverage. Red lines mark average coverage. White fields represent control (CR) and other non-coding regions (nc). Color codes: Red: $\mathrm{C}$ to $\mathrm{T}$ substitutions; Blue: G to A substitutions; Grey: All other substitutions; Orange: Soft-clipped bases; Green: Deletions relative to the reference; Purple: Insertions relative to the reference. Subfossil fragments (Philolithus actuosus) used in the extraction process were illustrated for 34,355 ybp sample.

arrangement for Philolithus actuosus is consistent with those reported for other darkling beetle species ${ }^{53}$, with the addition of an intergenic non-coding region following nad2 (Fig. 1). This gene arrangement is also consistent with the inferred ancestral mitochondrial gene order in insects ${ }^{54}$. Partial mitochondrial genomes were recovered for the samples dated at $\sim 8480$ and $\sim 34,355 \mathrm{ybp}$ (Fig. 1). The average read depth for those older samples was low. For the $\sim 8480 \mathrm{ybp}$ sample, $72.8 \%$ of the aligned mitochondrial bases present in the matrix were covered by at least one read, with an average read coverage across the mitogenome of 1.6X. For the $34,355 \mathrm{ybp}$ sample, $12.3 \%$ of the aligned mitochondrial bases were covered by at least one read, with an average read coverage across the mitogenome of $0.13 \mathrm{X}$. For the $\sim 16,610$ ybp sample no unambiguous sequences were recovered (Fig. 1 ).

In the case of all analyzed ancient DNA libraries, the highest number of mitochondrial reads mapped to sequences originating from Philolithus actuosus (Fig. 2a), which based on morphological traits was suspected to constitute the closest reference. The number of mapped reads drops by over $60 \%$ in more distantly related references, i.e. Philolithus aegrotus, Pelecyphorus contortus, Stenomorpha consobrina, and Machla setosa. This tendency was not observed in all $28 \mathrm{~S}$ sequences, where for $\sim 1615 \mathrm{ybp}, \sim 8480 \mathrm{ybp}$, and $\sim 34,355 \mathrm{ybp}$ samples, the number of recovered reads remained on a similar level regardless of the reference sequences used (Fig. 2b). This is likely due to the relatively conserved nature of $28 \mathrm{~S}$ in comparison to the faster evolving mitogenome ${ }^{55}$. From the sequenced beetle extraction blanks, a single read of 52 bp mapped to the tRNA-Trp when using Philolithus 
a) mitogenomes

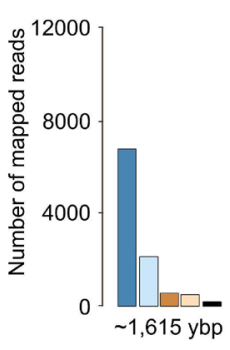

b) 285

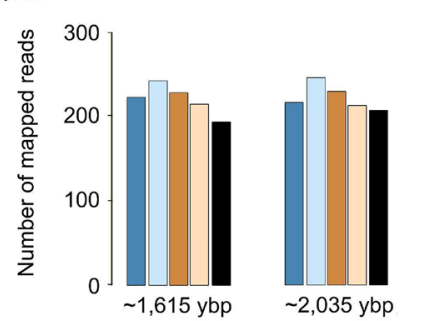

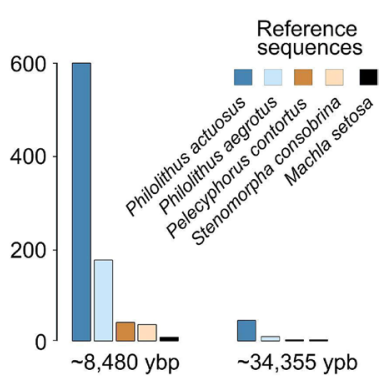

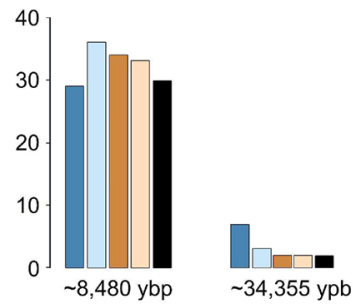

Figure 2. Comparison of the number of successfully recovered mitochondrial (a) and nuclear (b) reads from the analyzed libraries representing ancient samples mapped to different reference sequences. Subsequent reference sequences represent species increasingly less related to the analyzed ancient species based on morphological traits.

actuosus or Philolithus aegrotus as the reference sequence. A GenBank search (blastn) placed the sequence as potentially beetle DNA (Scraptiidae: Anaspis, max. score 81.5), but it is unclear if this was from the extractions or environmental DNA. The one Pimeliinae mitogenome in GenBank (from Asbolus verrucosus) was not recovered in the top 100 sequences producing significant alignments (max scores 81.5-60.8). No other reads from the extraction blanks, nor any from the library blank mapped to any of the references.

The results of the MapDamage analysis of the mapped mitochondrial reads are presented on Fig. 1. Provided patterns concern the UDG-treated DNA, and therefore should be interpreted with caution ${ }^{28}$. Furthermore, due to scarcity of obtained reads, the MapDamage profiles recovered for older samples (i.e., $~ 8480$ and $~ 34,355$ ybp) are not alone conclusive. On the other hand, the mapped reads for the $\sim 1615$ and $\sim 2035$ ybp samples show somewhat elevated levels of $\mathrm{C} \rightarrow \mathrm{T}$ substitutions relative to the reference genome at their terminal ends, which is expected for ancient samples ${ }^{56}$. At the same time, it has to be noticed that these samples are not old enough to expect massive deamination ${ }^{57}$.

Phylogenetic placement of ancient specimens. To test the reliability of the DNA recovery process, phylogenetic analyses were performed based on a matrix composed of 15 mitochondrial loci (16S, 12S, atp6, atp8, cob, COI-III, NAD1-6) and the D1-D3 region of nuclear ribosomal 28S, for a total of 13,926 bp. Selected species representing Asidini were incorporated in order to identify the ancient samples to species level, with ancient DNA reads mapped to multiple taxa and the mitochondrial genes for the two most recent samples assembled de novo (Supplement 1). The greatest read coverages for the ancient samples were recovered when Philolithus actuosus was used as the reference taxon (Supplement 2). All ancient samples from which DNA was recovered were placed as Philolithus actuosus with high probability (PP: 1.00 and BS: 97; Fig. 3). This species currently occurs in and around Joshua Tree National Park in southeastern California and this study indicates that it has likely persisted in the region for some time.

Additional phylogenetic analyses were conducted with ancient samples mapped to multiple references (Philolithus actuosus, Philolithus aegrotus, Pelecyphorus contortus, Stenomorpha consobrina, and Machla setosa), and using different read mapping parameters, to explore potential reference bias (Supplements 3, 4) and sequence recovery rates (Fig. 2). Minor differences between mapped sequences using seed versus seedless parameters ( hood topologies; hence, assemblies using seed parameters were used for subsequent analyses. While a degree of reference bias was evident in the phylogenetic analyses, it had only a slight impact on the overall placement of the ancient samples. The majority of ancient libraries mapped to different references were still recovered as Philolithus actuosus, with relatively small genetic differences between each other. Five alternate assemblies were placed differently when all references were used. The $\sim 8480$ ybp library mapped to Pelecyphorus contortus and Stenomorpha consobrina were both recovered within Philolithus, but not with other Philolithus actuosus sequences. The $\sim 1615 \mathrm{ybp}, \sim 2035 \mathrm{ybp}, \sim 8485 \mathrm{ybp}$ libraries mapped to Machla setosa were all recovered outside of the genus Philolithus (Supplement 4). However, in all of these cases the number of mapped reads and the total number of base pairs present in the matrix (i.e., most reads mapped to conserved regions) were extremely low when compared to phylogenetically closer references (Fig. 2a, Supplement 2). Hence, the phylogenetic reliability of the resulting assembled sequences is questionable. For example, only 12 reads were recovered from the $\sim 8480$ ybp sample mapped to Machla setosa (Fig. 2a, Supplement 2). Only one of these reads mapped to a protein coding 


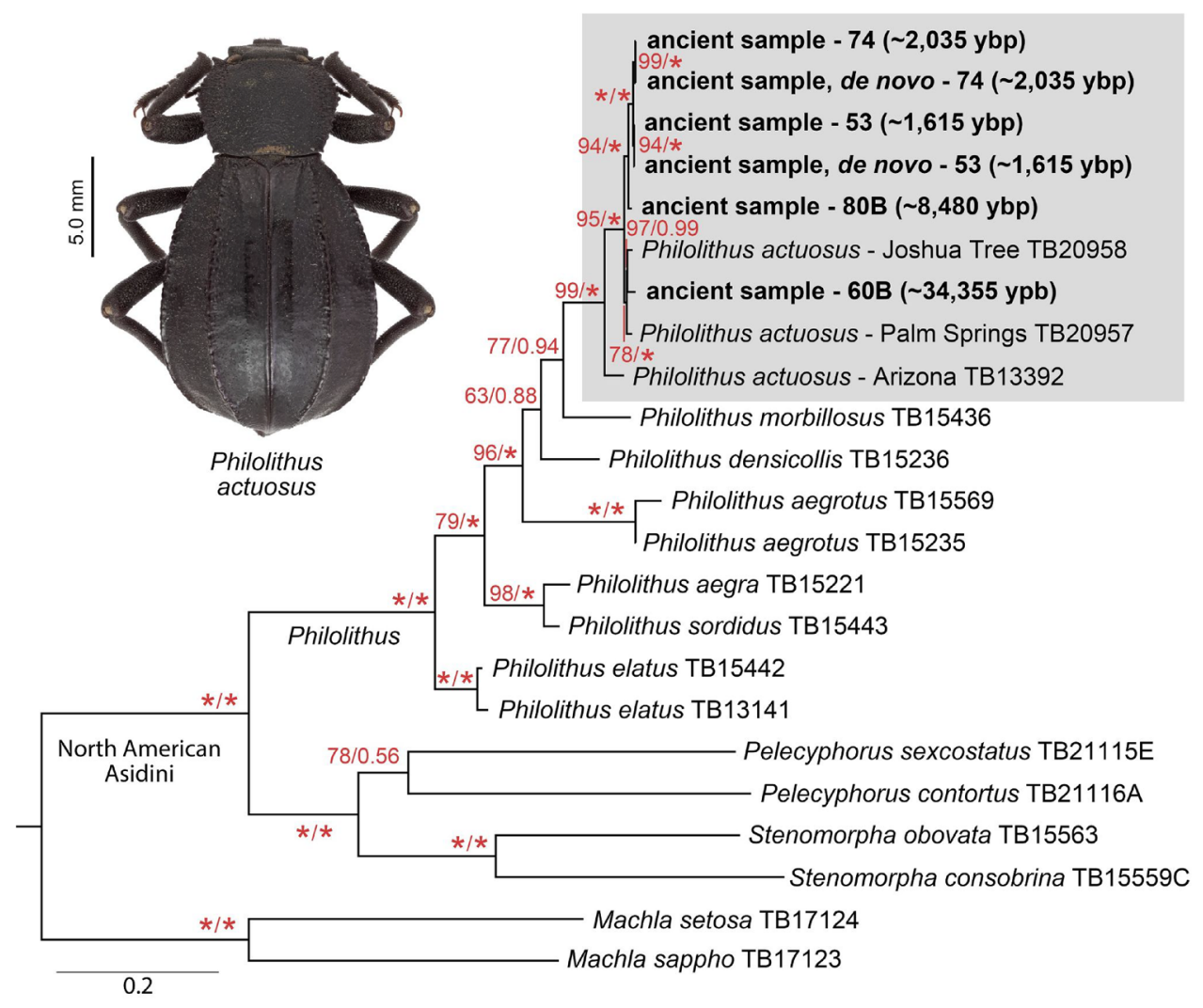

Figure 3. Phylogenetic placement of recovered ancient samples. Maximum likelihood tree generated by analysis of a concatenated dataset of 13,926 bp (16 s, 28 s, 12 s, atp6, atp8, cob, COI-III, NAD1-6) in IQ-Tree with ancient midden samples assembled de novo or using Philolithus actuosus (TB20958) as the reference. Total number of bp used for each taxa is listed in Supplemental Table 1. Posterior probabilities (PP) from Bayesian analyses are displayed on the right, bootstrap values from IQ-Tree on the left. An asterisk indicates either PP of 1.0 or bootstrap value of $100 \%$.

gene (NAD4), and was identical to that portion of the reference. The remaining 11 reads mapped to tRNAs or rRNAs, which could be mismappings or mappings to highly conserved regions. Bayesian phylogenetic analyses using alternate references (i.e., any reference other than $P$. actuosus) uniformly failed to converge when run for 20 million generations.

\section{Discussion}

Challenges of ancient DNA studies using insects. Compared to the number of recent publications dealing with animal aDNA ${ }^{2,4-6}$, the scarcity of insect studies is striking. To our knowledge, this is the first targeted study on insect aDNA using high-throughput sequencing, despite the widespread availability of nextgeneration sequencing technologies over the past $\sim 15$ years. We assume that the lack of such studies is partially explained by difficulties with reliably identifying ancient material, which makes insects an unappealing research subject for some scientists. The species diversity within insect communities in any given area is also often considerably higher than that of other animal groups. For example, within the borders of Białowieża Primaeval Forest, Europe's largest surviving primeval forest, 59 mammal species (including rodents and bats) have been recorded $^{58}$, while around 9,600 insect species are known to inhabit the area ${ }^{59}$. In one instance, the coexistence of 20 relatively closely related and morphologically convergent (difficult to distinguish) coprophagous scarab beetles was reported from just a small fragment $\left(200 \mathrm{~m}^{2}\right)$ of that ecosystem ${ }^{60}$. As many insect groups lack comprehensive, well-illustrated taxonomic contributions, reliable species identifications, especially for damaged subfossil specimens, can often only be made by taxonomists specializing in a specific group (generally at the ordinal or family level) or geographic region, which generally imposes a need for cooperation from multiple taxon experts to solve a particular problem in a given area.

On the other hand, insect identification based solely on molecular data is also problematic. Compared to vertebrates (specifically birds and mammals), many insect groups lack published phylogenetic hypotheses and/ or molecular data to explore the placement of ancient taxa. For example, prior to this study there was a single publication available on the phylogeny of North American Asidini ${ }^{61}$ - the tribe containing our analyzed ancient specimens, while other geographic components of this tribe (especially African and South American taxa) have yet to be put within a phylogenetic framework, with no sequences currently available in GenBank. To address this limitation in the context of the current study, we sequenced the mitogenomes of seven additional Asidini 
species from modern samples and two museum specimens (collected $~ 54 \mathrm{ybp}$ ) of Philolithus actuosus from the geographic region of interest (Fig. 3). Globally, the scarcity of reference sequences prevents molecular specieslevel identification, which explains why most of the available insect aDNA studies were limited to higher classification levels ${ }^{11,13}$. Furthermore, the lack of available insect genomes in comparison to their diversity complicates genome reconstruction ${ }^{4}$, as mapping efficiency drops rapidly with increasing phylogenetic distance ${ }^{52,62}$. Taking this into account, we assume that the nuclear endogenous content presented here for the analyzed ancient samples (Table 1) is likely an underestimate, given that the subfamily containing Tribolium castaneum (Tenebrioninae), the only available reference genome for Tenebrionidae, is estimated to have diverged from Pimeliinae, the subfamily containing Philolithus, $\sim 145$ million years ago ${ }^{51}$. This illustrates the lack of genomic resources available for entomological studies (the order Coleoptera contains $\sim 450,000$ described species with five published genomes) when compared to the existing publicly available resources for the study of mammals $(\sim 6500$ described species with over 119 published genomes). It also highlights the fact that in order to conduct aDNA-based research within the majority of insect groups, preliminary genomic sequencing and phylogenetic efforts on modern taxa are first needed to produce the required resources for aDNA studies.

In order to avoid some of the above mentioned restrictions, alternative assembly approaches can be considered [e.g. ${ }^{63,64}$. Data analyzed here suggest that the de novo assembly approach can be used to potentially accelerate ancient DNA studies on at least some groups of insects, as the sequences obtained by using this method were almost fully convergent with the ones derived from the reference-based technique using a museum specimen from the same species as the samples (Fig. 3). The advantage of de novo assembly for aDNA samples has already been widely postulated in many similar cases when closely related reference genomes were not available ${ }^{30}$. In addition, de novo assemblies can be used to identify longer deletions or genomic rearrangements ${ }^{65}$. However, due to the fragmentation of ancient DNA, de novo assembly is not always feasible, as resulting assembly quality strongly depends on sequencing coverage, read length and its accuracy ${ }^{66}$. As a consequence, especially in cases of poorly investigated groups, a variety of different approaches should be implemented to assess the accuracy of molecular identifications. In this study, de novo mitogenome assemblies were produced for the two most recent aDNA samples $(\sim 1615 \mathrm{ybp}$ and $\sim 2035 \mathrm{ybp})$ to compare the accuracy of reference based assemblies using modern species. However, de novo assemblies could not be made for the older samples and identifying midden fragments to species is often not possible based on morphology.

Packrat middens: a reliable source of subfossilized insects. Although the recovered MapDamage profiles are not alone conclusive to validate the authenticity of the obtained sequences, especially in the case of two older samples where not enough reads were recovered (Fig. 1), it has to be noted that, due to the nature and specific processing of the midden samples, the risk of contamination has been largely minimized. Namely, the midden structure, due to its compact/fossilised nature, does not allow modern organisms to penetrate it and therefore be subsequently incorporated within the deeper layers of its matrix ${ }^{67}$. As stated before, the outer layer of the investigated middens has been removed prior to other laboratory procedures preventing potential inclusion of more recent subfossilizations within the sampled layers ${ }^{23,24}$. Furthermore, the material was initially sorted in a facility in which no modern samples of darkling beetles were being investigated. The identification process was also carried in isolation using sterilized laboratory equipment. Finally, the processed ancient samples represent the first beetle samples analysed in the ancient DNA laboratory of the Evolutionary Adaptive Genomics research group in Potsdam, Germany. Given the Nearctic distribution of the flightless Philolithus actuosus, contamination during the extraction or library preparation procedures seems unlikely.

For this project, all samples were first identified from previously studied middens ${ }^{23,24}$ to the genus Philolithus, primarily based on the morphology of the legs, which were also used for extractions. All of the samples that yielded endogenous beetle DNA were from Joshua Tree National Park (JTNP), and identified as Philolithus actuosus based on both morphology and sequence data. While several additional Philolithus species have been described from central California ${ }^{61}$, all are considered synonyms of $P$. actuosus in an upcoming revision of the genus. Philolithus species are fairly ubiquitous flightless detritivores in western North American deserts, with $P$. actuosus being one of the largest (length $\sim 15-35 \mathrm{~mm}$ ) macro-invertebrates in central and southern California. The species' persistence or frequent repatriation within JTNP adds further support to the evidence from vegetation data that the region has been relatively stable and xeric over the last $\sim 34,000$ years ${ }^{23}$.

Sequence data from the Sierra Juarez mountain range (Baja California, Mexico) fragments $(\sim 16,610 \mathrm{ybp})$ could not be assembled to any of the Tenebrionidae references, despite being processed and stored using the same protocols as the JTNP midden samples. This may be due to the stochastic history of packrat middens or could indicate the need for updated protocols for sample preservation and processing to increase endogenous DNA yield. In contrast to bone, systematic studies trying to optimize DNA extraction from subfossil insect remains have yet to be undertaken. We assume that insect aDNA yield can be further increased by tailoring methods to extract subfossils from the midden matrix as well as optimizing DNA extraction buffers for insect remains. Current protocols include rehydration steps that may negatively impact aDNA quality. Furthermore, because all of the subfossils analyzed were primarily intended for morphological studies, they were stored at room temperature for over a decade ${ }^{23,24}$, which has also been argued to negatively affect ancient DNA yields, at least from bone ${ }^{68}$. Future insect aDNA studies could address these potential methodological shortcomings, for example by bleaching the samples ${ }^{69}$, breaking down the midden matrix in ethanol or directly in the extraction buffer, and storing specimens at lower temperatures. We predict that the optimization of extraction methods for subfossil insects, and potentially the application of hybridization capture techniques, will substantially increase the endogenous DNA content and sequence complexity of aDNA libraries, allowing for more comprehensive recovery of nuclear DNA, as short nuclear ribosomal DNA (28S) fragments were already reported here ${ }^{24}$. 
Utility and prospects of ancient DNA studies on insects. Insects are ubiquitous and play important roles in ecosystems, which makes them an interesting subject for various types of ecological investigations, including ones based on aDNA. Specifically, insects have invaded every niche, except the oceanic benthic zone ${ }^{70}$. They create the biological foundation for all terrestrial ecosystems as they pollinate plants ( $~ 85 \%$ of angiosperms are pollinated by insects), disperse seeds ${ }^{71}$, cycle nutrients, maintain soil structure and fertility ${ }^{72}$, control populations of other organisms, and serve as a food source for other taxa ${ }^{73}$, as well as producing byproducts such as honeydew. Compared to large mammals - the group most commonly used in aDNA studies-many insect species have short generation times and high reproductive rates, which allows them to more rapidly respond to climate change, especially temperature fluctuation ${ }^{74}$. Ample evidence shows that insects are one of the first groups to respond to ongoing climate change $\mathrm{e}^{75}$. For example, a study on butterflies in the United Kingdom showed that many species failed to track recent climate warming due to a lack of suitable habitat ${ }^{76}$. Furthermore, insects were shown to be reliable indicators of past climatic changes in the Quaternary, providing original insights on the topic ${ }^{77}$. In light of aDNA based population studies, it is important to note that contrary to large mammals ${ }^{78}$, ancient populations of insects were likely to be less influenced by human activity in the pre-Anthropocene period. Therefore, reconstruction of their history can provide reliable reference for distinctions between natural and human-caused evolutionary bottlenecks observed in other phylogenetic groups. It needs to be noted that this potential is almost entirely unexploited, as only a handful of studies using Bayesian skyline plots on insects exist $^{79}$. Lastly, given the complicated life histories of many insect groups (particularly Holometabola), a single insect species can potentially provide insights on more than one ecosystem, as larvae and adults often inhabit different environments, e.g. soil dwelling larvae and epigeic imagines as in darkling beetles.

In the context of insect aDNA-based climatic and population studies, darkling beetles (Tenebrionidae) are a promising group for future research, as they are extremely abundant in midden samples ${ }^{80}$ and, at least in some cases, are identifiable to species based on small body fragments, such as legs, pronota or elytra (Fig. 1). These features could allow for more detailed population studies of specific species that incorporate aDNA ${ }^{79,81}$. On the larger scale, the family includes $\sim 20,000$, mostly xerophilous and apterous (limited dispersal abilities) species distributed globally ${ }^{51}$, which makes it a suitable group for climate change studies. Moreover, ongoing phylogenetic and phylogenomic studies on the family (e.g. ${ }^{20,22,61}$ ) are constantly improving our understanding of the groups evolutionary history and providing new reference sequences for more detailed aDNA investigations.

In conclusion, this study pictures rodent middens as a rich and unexplored source of well-preserved insect aDNA from arid parts of the globe that can be used for various climatic and/or biological studies. The presence of endogenous beetle aDNA was recorded in samples as old as $~ 34,355 \mathrm{ybp}$ (Fig. 1), in quantities sufficient for inclusion in phylogenetic analyses with both modern and museum specimens (Fig. 3). This potentially enables the incorporation of aDNA data, including that generated in this study, in more detailed population studies, such as single nucleotide polymorphisms (SNPs) analyses ${ }^{81}$.

\section{Data availability}

All newly generated sequences were submitted to NCBI GenBank (Accession numbers MZ313233MZ313247, MZ313469-MZ313476, MZ322320-MZ322327, MZ342776- MZ342786, MZ351464MZ351487), while raw sequencing reads are available from the Sequence Read Archive (Accession numbers SRR14723036-SRR14723047).

Received: 30 January 2021; Accepted: 26 May 2021

Published online: 16 June 2021

\section{References}

1. Higuchi, R., Bowman, B., Freiberger, M., Ryder, O. A. \& Wilson, A. C. DNA sequences from the quagga, an extinct member of the horse family. Nature 312, 282-284 (1984).

2. Dabney, J. et al. Complete mitochondrial genome sequence of a Middle Pleistocene cave bear reconstructed from ultrashort DNA fragments. Proc. Nat. Acad. Sci. USA 110, 15758-15763 (2013).

3. Gansauge, M.-T. \& Meyer, M. Single-stranded DNA library preparation for the sequencing of ancient or damaged DNA. Nat. Protoc. 8, 737-748 (2013).

4. Palkopoulou, E. et al. Genomic history of extinct and living elephantids. Proc. Nat. Acad. Sci. USA 115(11), E2566-E2574 (2018).

5. Rawlence, N. J. et al. Ancient DNA and morphometric analysis reveal extinction and replacement of New Zealand's unique black swans. Proc. Biol. Sci. 2017(284), 20170876 (1859).

6. Der Sarkissian, C. et al. Ancient DNA analysis identifies marine mollusc shells as new metagenomic archives of the past. Mol. Ecol. Resour. 2017(17), 835-853 (2017).

7. Pont, C. et al. Paleogenomics: reconstruction of plant evolutionary trajectories from modern and ancient DNA. Genome Biol. 20, 29 (2019).

8. Forin, N. et al. Next generation sequencing of ancient fungal specimens: the case of the saccardo mycological Herbarium. Front. Ecol. Evol 15, 150. https://doi.org/10.3389/fevo.2018.00129 (2018).

9. Larsen, B. B., Cole, K. L. \& Worobey, M. Ancient DNA provides evidence of 27,000-year-old papillomavirus infection and longterm codivergence with rodents. Virus Evol. https://doi.org/10.1093/ve/vey014 (2018).

10. Cano, R. J., Poinar, H. N., Pieniazek, N. J., Acra, A. \& Poinar, G. O. Amplification and sequencing of DNA from a 120-135-millionyear-old weevil. Nature 363(6429), 536-538 (1993).

11. Reiss, R. A. Ancient DNA from ice age insects: proceed with caution. Quatern. Sci. Rev. 25, 1877-1893 (2006).

12. Chapco, W. \& Litzenberger, G. A DNA investigation into the mysterious disappearance of the Rocky Mountain grasshopper, mega-pest of the 1800s. Mol. Phylogenet. Evol. 30, 810-814 (2004).

13. Willerslev, E. et al. Ancient Biomolecules from deep ice cores reveal a forested Southern Greenland. Science 317, 111-114 (2007).

14. Thomsen, P. F. et al. Non-destructive sampling of ancient insect DNA. PLoS ONE 4(4), e5048 (2009).

15. Birks, H. J. B. \& Birks, H. H. How have studies of ancient DNA from sediments contributed to the reconstruction of Quaternary floras?. New Phytol. 209, 499-506 (2016). 
16. Moore, G., Tessler, M., Cunningham, S. W., Betancourt, J. \& Harbert, R. Paleo-metagenomics of North American fossil packrat middens: past biodiversity revealed by ancient DNA. Ecol. Evol. https://doi.org/10.1002/ece3.6082 (2020).

17. Betancourt, J. L. et al. (eds) Packrat Middens: The Last 40,000 years of Biotic Change (University of Arizona Press, 1990).

18. Butterfield, B., Holmgren, C. A., Anderson, S. L. \& Betancourt, J. L. Life history traits predict colonization and extinction lags of desert plant species since the Last Glacial Maximum. Ecology 100, e02817 (2019).

19. Wood, J. R. et al. Ancient parasite DNA from late Quaternary Atacama Desert rodent middens. Quat. Sci. Rev 226, 106031 (2019).

20. Kanda, K., Pflug, J. M., Sproul, J. S., Dasenko, M. A. \& Maddison, D. R. Successful recovery of nuclear protein-coding genes from small insects in museums using Illumina sequencing. PLoS ONE 11(3), e0151124 (2015).

21. Sproul, J. S. \& Maddison, D. R. Sequencing historical specimens: successful preparation of small specimens with low amounts of degraded DNA. Mol. Ecol. Resour 17, 1183-1201 (2017).

22. Kamiński, M. J., Kanda, K., Lumen, R., Smith, A. D. \& Iwan, D. Molecular phylogeny of Pedinini (Coleoptera, Tenebrionidae) and its implications for higher-level classification. Zool. J. Linn. Soc. 185(1), 77-97 (2019).

23. Holmgren, C. A., Betancourt, J. L. \& Rylander, K. A. A long-term vegetation history of the Mojave-Colorado desert ecotone at Joshua Tree National Park. J. Quat. Sci. 25, 222-236 (2010).

24. Holmgren, C. A. et al. Evidence against a Pleistocene desert refugium in the Lower Colorado River Basin. J. Biogeogr. 41, 1769-1780 (2014).

25. Rohland, N., Siedel, H. \& Hofreiter, M. Nondestructive DNA extraction method for mitochondrial DNA analyses of museum specimens. Biotechniques 36(5), 814-821 (2004).

26. Taron, U. H., Lell, M., Barlow, A. \& Paijmans, J. L. A. Testing of Alignment Parameters for ancient samples: evaluating and optimizing mapping parameters for ancient samples using the TAPAS tool. Genes 9(3), 157 (2018).

27. Pearl, L. H. Structure and function in the uracil-DNA glycosylase superfamily. Mutat. Res. 460, 165-181 (2000).

28. Briggs, A. W. et al. Removal of deaminated cytosines and detection of in vivo methylation in ancient DNA. Nucl. Acids Res. 38, 87 (2010).

29. Sheng, G.-L. et al. Paleogenome reveals genetic contribution of extinct Giant Panda to extant populations. Curr. Biol. 29, 16951700.e6 (2019).

30. Westbury, M. et al. A mitogenomic timetree for Darwin's enigmatic South American mammal Macrauchenia patachonica. Nat. Commun. 8, 15951 (2017).

31. Green, P. \& Ewing B. Phred, 2002 Version 0.020425 c. Available from: http://phrap.org.

32. Green, P. Phrap, 1999 Version 0.990329. Available from: http://phrap.org.

33. Maddison. D. R., Maddison, W. P. Mesquite: a modular system for evolutionary analysis. Version 3.612019

34. Bolger, A. M., Lohse, M. \& Usadel, B. Trimmomatic: a flexible trimmer for Illumina Sequence Data. Bioinformatics 30, 2114-2120 (2014).

35. Nurk, S., Bankevich, A., Antipov, D., Gurevich, A., Korobeynikov, A., Lapidus, A., Prjibelsky, A., Pyshkin, A., Sirotkin, A., Sirotkin, Y, et al. Assembling Genomes and Mini-Metagenomes from Highly Chimeric Reads. In: Deng, M., Jiang, R., Sun, F. \& Zhang, X. (eds), Res Comput Mol Biol. 7821: (Springer Berlin Heidelberg, Berlin, (2013).

36. Hahn, C., Bachmann, L. \& Chevreux, B. Reconstructing mitochondrial genomes directly from genomic next-generation sequencing reads: a baiting and iterative mapping approach. Nucl. Acids Res. 41(13), e129. https://doi.org/10.1093/nar/gkt371 (2013).

37. Li, H. \& Durbin, R. Fast and accurate short read alignment with Burrows-Wheeler Transform. Bioinformatics 25, 1754-1760 (2009).

38. Li, H. et al. 1000 Genome Project Data Processing Subgroup. The Sequence Alignment/Map format and SAMtools. Bioinformatics 25(16), 2078-2079. https://doi.org/10.1093/bioinformatics/btp352 (2009).

39. Li, H. A statistical framework for SNP calling, mutation discovery, association mapping and population genetical parameter estimation from sequencing data. Bioinformatics 27(21), 2987-2993 (2011).

40. Jónsson, H., Ginolhac, A., Schubert, M., Johnson, P. \& Orlando, L. mapDamage2.0: fast approximate Bayesian estimates of ancient DNA damage parameters. Bioinformatics https://doi.org/10.1093/bioinformatics/btt193 (2013).

41. Bernt, M. et al. MITOS: improved de novo metazoan mitochondrial genome annotation. Mol. Phylogenet. Evol. 69, 313-319. https://doi.org/10.1016/j.ympev.2012.08.023 (2013).

42. Cameron, S. L. How to sequence and annotate insect mitochondrial genomes for systematic and comparative genomics research. Sys. Entomol. 39, 400-411 (2014).

43. Quinlan, A. R. \& Hall, I. M. BEDTools: a flexible suite of utilities for comparing genomic features. Bioinformatics 26, 841-842. https://doi.org/10.1093/bioinformatics/btq033 (2010).

44. TGSC. The genome of the model beetle and pest Tribolium castaneum. Nature 452, 949-955 (2008).

45. Katoh, K. \& Standley, D. M. MAFFT multiple sequence alignment software version 7: improvements in performance and usability. Mol. Biol. Evol. 30, 772-780. https://doi.org/10.1093/molbev/mst010 (2013).

46. Miller, M. A., Pfeiffer, W. \& Schwartz, T. Creating the CIPRES Science Gateway for inference of large phylogenetic trees. In Proceedings of the Gateway Computing Environments Workshop, (2010).

47. Ronquist, F. et al. MrBayes 3.2: efficient Bayesian phylogenetic inference and model choice across a large model space. Syst. Biol. 61, 539-542 (2012).

48. Nguyen, L.-T., Schmidt, H. A., von Haeseler, A. \& Minh, B. Q. IQ-TREE: a fast and effective stochastic algorithm for estimating maximum likelihood phylogenies. Mol. Biol. Evol. 32, 268-274. https://doi.org/10.1093/molbev/msu300 (2015).

49. Rambaut, A., Drummond, A. J., Xie, D., Baele, G. \& Suchard, M. A. Posterior summarisation in Bayesian phylogenetics using Tracer 1.7. Syst. Biol. 2018, syy032. https://doi.org/10.1093/sysbio/syy032 (2018).

50. Minh, B. Q., Nguyen, M. A. \& von Haeseler, A. Ultrafast approximation for phylogenetic bootstrap. Mol. Biol. Evol. 30(5), 11881195. https://doi.org/10.1093/molbev/mst024 (2013).

51. Kergoat, G. J. et al. Cretaceous environmental changes led to high extinction rates in a hyperdiverse beetle family. BMC Evol. Biol. 14, 220. https://doi.org/10.1186/s12862-014-0220-1 (2014).

52. Prüfer, K. et al. Computational challenges in the analysis of ancient DNA. Genome Biol. 11(5), R47 (2010).

53. Song, N., Liu, H.-Y., Yang, X.-J., Zhao, X.-C. \& Lin, A. L. Complete mitochondrial genome of the darkling beetle Gonocephalum outreyi (Coleoptera: Tenebrionidae) with phylogenetic implications. J. Asia Pac. Entomol. 21, 721-730 (2018).

54. Cameron, S. L. Insect mitochondrial genomics: implications for evolution and phylogeny. Annu. Rev. Entomol. 59, 95-117 (2014).

55. Ruttkay, H., Solignac, M. \& Sperlich, D. Nuclear and mitochondrial ribosomal RNA variability in the obscura group of Drosophila. Genetica 85, 143-179 (1992).

56. Ginolhac, A., Rasmussen, M., Gilbert, M. T. P., Willerslev, E. \& Orlando, L. mapDamage: testing for damage patterns in ancient DNA sequences. Bioinformatics 27, 2153-2155 (2011).

57. Sawyer, S., Krause, J., Guschanski, K., Savolainen, V. \& Pääbo, S. Temporal patterns of nucleotide misincorporations and DNA fragmentation in ancient DNA. PLoS ONE 7(3), e34131 (2012).

58. Zub, K. Mammals. In Białowieża National Park, know it, understand it, protect it (eds Okołów, C. et al.) (Białowieski Park Narodowy, 2009).

59. Gutowski, M. G. \& Jaroszewicz, B. Białowieża Primeval Forest as a refuge of the European entomofauna. Wiad. Entomol. 23, 67-97 (2004).

60. Kamiński, M. J., Byk, A. \& Tykarski, P. Seasonal and diel activity of dung beetles (Coleoptera: Scarabaeoidea) attracted to European bison dung in Białowieża Primeval Forest. Coleopt Bull 69, 83-90 (2015). 
61. Smith, A. D. Phylogenetic revision of the North American Asidini (Coleoptera: Tenebrionidae). Syst. Entomol. 38, 585-614 (2013).

62. Shapiro, B. \& Hofreiter, M. A. paleogenomic perspective on evolution and gene function: new insights from ancient DNA. Science 343(6169), 1236573. https://doi.org/10.1126/science.1236573 (2014).

63. Al-Nakeeb, K., Petersen, T. N. \& Sicheritz-Pontén, T. Norgal: extraction and de novo assembly of mitochondrial DNA from whole-genome sequencing data. BMC Bioinform. 18, 510 (2017).

64. Allen, J. M., Huang, D. I., Cronk, Q. C. \& Johnson, K. P. aTRAM - automated target restricted assembly method: a fast method for assembling loci across divergent taxa from next-generation sequencing data. BMC Bioinform. 16, 98 (2015).

65. Seitz, A. \& Nieselt, K. Improving ancient DNA genome assembly. PeerJ 5, e3126 (2017).

66. Myers, E. W. A history of DNA sequence assembly. Inf. Technol. 58, 1-7 (2016).

67. Lesser, M. R. \& Jackson, S. T. Reliability of macrofossils in woodrat (Neotoma) middens for detecting low-density tree populations. Paleobiology 37, 603-615 (2011).

68. Pruvost, M. et al. Freshly excavated fossil bones are best for amplification of ancient DNA. PNAS 104, 739-744 (2007).

69. Boessenkool, S. et al. Combining bleach and mild predigestion improves ancient DNA recovery from bones. Mol. Ecol. Resour. 17, 742-751 (2016).

70. Grimaldi, D. \& Engel, M. S. The Evolution of the Insects (Cambridge University Press, 2005).

71. de Vega, C., Arista, M., Ortiz, P. L., Herrera, C. M. \& Talavera, S. Endozoochory by beetles: a novel seed dispersal mechanism. Ann. Bot. 107, 629-637. https://doi.org/10.1093/aob/mcr013 (2011).

72. Hanski, I. \& Cambefort, Y. Dung Beetle Ecology (Princeton University Press, 1991).

73. Majer, J. D. The Conservation and Study of Invertebrates in Remnants of Native Vegetation. In Nature Conservation: The Role of Remnants of Native Vegetation (eds Saunders, D. A. et al.) (Surrey Beatty and Sons, 1987).

74. Scherm, H., Sutherst, R. W., Harrington, R. \& Ingram, J. S. I. Global networking for assessment of impacts of global change on plant pests. Environ. Pollut. 108, 333-341 (2000).

75. Wilson, R. J., Davies, Z, G. \& Thomas C. D. Insects and climate change: processes, patterns and implications for conservation. In: Insect Conservation Biology. In Proceedings of the Royal Entomological Society's 22nd Symposium. (CAB International Publishing, Wallingford, 2007).

76. Hill, J. K. et al. Responses of butterflies to 20th century climate warming: implications for future ranges. Proc. Royal Soc. B. 269, 2163-2171 (2002).

77. Elias, S. A., Van Devender, T. R. \& De Bac, R. Insect fossil evidence of Late Glacial and Holocene environments in the Bolson De Mapimi, Chihuahuan Desert, Mexico: Comparisons with the paleobotanical Record. Palaios 10(5), 454-464 (1995).

78. Barnes, I. et al. Genetic structure and extinction of the woolly mammoth, Mammuthus primigenius. Curr. Biol. 17, 1072-1075 (2007).

79. Su, L. N. et al. Population genetic structure and historical demography of the ground beetle Chlaenius costiger in the Tsinling-Dabashan Mountains of central China. Genet. Mol. Res. 14, 3579-3589 (2015).

80. Elias, S. A. \& Van Devender, T. R. Insect fossil evidence of late quaternary environments in the Northern Chihuahuan desert of Texas and New Mexico: comparisons with the paleobotanical record. Southwest. Nat. 37, 101-116 (1992).

81. Wutke, S. \& Ludwig, A. Targeted PCR Amplification and Multiplex Sequencing of Ancient DNA for SNP Analysis. In: Shapiro, B., Barlow, A., Heintzman, P., Hofreiter, M., Paijmans, J. \& Soares, A. (eds) Ancient DNA. Methods Mol. Biol., 1963. (Humana Press, New York, 2019).

\section{Acknowledgements}

Funding was provided by the NSF ARTS Program (DEB \#s 1523605, 1754630, and 2009247), the NSF Postdoctoral Fellowship in Biology (DEB\# 1612282), the National Science Centre, Poland (OPUS-19 Project 2020/37/B/NZ8/02496), NIFA (Hatch Project No. IND10004973), and the Northern Arizona University Faculty Grants Program. The authors would like to thank Gene Hall for critical review of the manuscript prior to submission, and the anonymous reviewers for valuable feedback and comments. Mention of trade names or commercial products in this publication is solely for the purpose of providing specific information and does not imply recommendation or endorsement by the USDA. The USDA is an equal opportunity provider and employer.

\section{Author contributions}

A.D.Sm., M.H., K.K., and M.J.K. designed and led the study. J.L.B. and C.A.H. provided the sample for analysis. M.J.K., E.H., and F.A. generated the genetic data. A.D.Sw., A.D.Sm., M.J.K., E.H., F.A., and K.K. analyzed the genetic data. A.D.Sm., M.J.K. interpreted the results. A.D.Sm. and M.J.K. wrote the manuscript with input from A.D.Sw. and the remaining authors.

\section{Competing interests}

The authors declare no competing interests.

\section{Additional information}

Supplementary Information The online version contains supplementary material available at https:/doi.org/10.1038/ s41598-021-91896-8.

Correspondence and requests for materials should be addressed to A.D.S.

Reprints and permissions information is available at www.nature.com/reprints.

Publisher's note Springer Nature remains neutral with regard to jurisdictional claims in published maps and institutional affiliations.

Open Access This article is licensed under a Creative Commons Attribution 4.0 International License, which permits use, sharing, adaptation, distribution and reproduction in any medium or format, as long as you give appropriate credit to the original author(s) and the source, provide a link to the Creative Commons licence, and indicate if changes were made. The images or other third party material in this article are included in the article's Creative Commons licence, unless indicated otherwise in a credit line to the material. If material is not included in the article's Creative Commons licence and your intended use is not permitted by statutory regulation or exceeds the permitted use, you will need to obtain permission directly from the copyright holder. To view a copy of this licence, visit http://creativecommons.org/licenses/by/4.0/.

(C) The Author(s) 2021 